\title{
The relationship between Myocardial SPECT and Fractional Flow Reserve: Is it drifting apart?
}

\author{
Michael Rees
}

Received: 1 December 2009/Accepted: 4 December 2009/Published online: 24 December 2009

(C) Springer Science+Business Media, B.V. 2009

In the paper, Tc-99 $\mathrm{m}$ sestamibi single photon emission computed tomography for guiding percutaneous coronary intervention in patients with multivessel disease: a comparison with quantitative coronary angiography and fractional flow reserve by Forster et.al. the authors correctly point out that FFR (Fractional Flow Reserve) was initially validated against non-invasive studies which included Thallium SPECT, Stress Echocardiography and standard exercise testing. In the paper by Pijls et.al.in 1995 which was one of the first validation studies of FFR [1] there were a significant number of negative SPECT and stress echo results at FFR values significantly lower than .75 although in all patients myocardial ischaemia was demonstrated on one of the three tests used. In the same study two patients had positive exercise tests and one patient a positive Thallium SPECT scan with FFR values significantly above .75. Later studies have confirmed that a FFR results can have a prognostic significance which can be better than

Editorial comment on the article of Förster et al. (doi:10.1007/s10554-009-9510-x).

\section{Rees ( $\square)$}

School of Medical Sciences, Bangor University, Brigantia Building, Penrallt Road, Bangor, Gwynedd Wales LL57 2AS, UK

e-mail: michael.rees@bangor.ac.uk; m.rees@bangor.ac.uk

URL: www.bangor.ac.uk
SPECT in a selected group of patients with untreated intermediate lesions after PCI of a severe lesion [2].

In contrast SPECT itself has a significant prognostic value in patients with low or intermediate risk of coronary disease and has been recommended as a first line diagnostic method in coronary disease by the UK National Institute of Clinical Excellence (http:// www.nice.org.uk/nicemedia/pdf/TA073guidance.pdf). A normal Myocardial SPECT scan has been shown in large studies to have a very good prognostic value with adverse event rates of $0.6 \%$ year quoted in one study of 7,376 consecutive patients [3]. The prognostic value of SPECT scanning may be improved by using cardiac gating [4] and when ejection fraction and end-systolic volumes are also considered as additional data the overall prognostic value of SPECT scanning improves further [5].

The patient conditions under which FFR is measured also have to be taken into account. In this study the patients had multivessel disease. Although a single stenosis in each vessel would not modify the result multiple stenoses in a vessel require a modified approach to FFR measurement [6] and patients with a prior myocardial infarction resulting in microvascular dysfunction [7] may also have a falsely elevated FFR but usually by $5 \%$ however in chronic myocardial infarction FFR may still be accurate [8].

So can the relative merits of these two tests be put into perspective? How also should we view the role of QCA (quantitative coronary angiography) in this context? This study concludes that SPECT gives a 
$41 \%$ of false positive and false negative results in the setting of multivessel disease examined invasively by QCA and FFR. These results are in accord with received wisdom in invasive cardiology of the usefulness of FFR measurements [9]. However the reference standard for FFR measurement validation is still the myocardial SPECT scan. There is no absolute answer to this issue but once the patient has reached the catheter laboratory it is clear that the method of choice for determining whether intervention should occur is FFR combined with angiography and quantitative coronary angiography improves the diagnostic power of the coronary angiogram. Greater use of these techniques should result in better long term outcomes for these patients [10].

SPECT studies will in the mean time still continue to be an important part of the diagnostic investigation of patients with coronary disease in particular to determine which patients will be referred for diagnostic angiography and intervention [11].

\section{References}

1. Pijls NHJ, de Bruyne B, Peels K, van der Voort PH, Bonnier HJRM, Bartunek J, Koolen JJ (1996) Measurement of fractional flow reserve to assess the functional severity of coronary-artery stenoses. NEJM 334(26):17031708

2. Chamuleau SAJ, van Eck-Smit BLF, Meuwissen M, Koch KT, Dijkgraaf MGW, Verberne HJ, Tijssen JGP, Piek JJ (2007) Long-term prognostic value of CFVR and FFR versus perfusion scintigraphy in patients with multivessel disease. Neth Heart J 15(11):369-374 (on behalf of the ILIAS investigators ${ }^{1}$ )

3. Hachamovitch R, Hayes S, Friedman JD, Cohen I, Shaw LJ, Germano G, Berman DS (2003) Determinants of risk and its temporal variation in patients with normal stress myocardial perfusion scans what is the warranty period of a normal scan? FACC JACC 41(8):1329-1340

4. Sharir F, Germano G, Kang X, Lewin HC, Miranda R, Cohen I, Agafitei RD, Friedman JD, Berman DS (2001) Prediction of myocardial infarction versus cardiac death by gated myocardial perfusion SPECT: risk stratification by the amount of stress-induced ischemia and the poststress ejection. J Nucl Med 42:831-837

5. Matsuo S, Nakajima K, Horie M, Nakae I, Nishimura T (2008) J-ACCESS investigators, prognostic value of normal stress myocardial perfusion imaging in Japanese population. Circ J 72(4):611-617

6. Pijls NH, De Bruyne B, Bech GJ et al (2000) Coronary pressure measurement to assess the hemodynamic significance of serial stenoses within one coronary artery: validation in humans. Circulation 102:2371-2377

7. Claeys MJ, Bosmans JM, Hendrix J et al (2001) Reliability of fractional flow reserve measurements in patients with associated microvascular dysfunction: importance of flow on translesional pressure gradient. Catheter Cardiovasc Interv 54:427-434

8. Usui Y, Chikamori T, Yanagisawa H et al (2003) Reliability of pressure-derived myocardial fractional flow reserve in assessing coronary artery stenosis in patients with previous myocardial infarction. Am J Cardiol 92:699-702

9. Tobis J, Azarbal B, Slavin L (2007) Assessment of intermediate severity coronary lesions in the catheterization laboratory. JACC 49(8):839-848

10. Tonino PAL, De Bruyne B, Pijls NHJ, Siebert U, Ikeno F, van't Veer M, Klauss V, Manoharan G, Engstrøm T, Oldroyd KG, Ver Lee PV, MacCarthy PA, Fearon WF (2009) Fractional flow reserve versus angiography for guiding percutaneous coronary intervention. NEJM 360(3) :213-224

11. Patel MR, Dehmer GJ, Hirshfeld JW, Smith PK, Spertus JA (2009) ACCF/SCAI/STS/AATS/AHA/ASNC 2009 Appropriateness Criteria for Coronary Revascularization A Report of the American College of Cardiology Foundation Appropriateness Criteria Task Force, Society for Cardiovascular Angiography and Interventions, Society of Thoracic Surgeons, American Association for Thoracic Surgery, American Heart Association, and the American Society of Nuclear Cardiology. Circulation 119:1330-1352 